\title{
Endovascular occlusion of a ruptured transitional aneurysm associated with a developmental venous anomaly
}

\author{
Case report
}

\author{
Andrew F. Ducruet, M.D., Christopher P. Kellner, M.D., E. Sander Connolly Jr., M.D., \\ ANd Philip M. Meyers, M.D.
}

Department of Neurological Surgery, Columbia University Medical Center, New York, New York

\begin{abstract}
Developmental venous anomalies (DVAs) represent a rare cause of intraparenchymal hemorrhage. This case demonstrates an unusual DVA associated with venous hypertension, arteriovenous shunting, and a ruptured transitional aneurysm. The authors describe the first use of embolization as a treatment method for an unstable ruptured transitional aneurysm associated with a DVA. This 33-year-old man suffered acute onset of headache, gait ataxia, and left hemiparesis. Computed tomography brain scans demonstrated a deep paramedian right frontal intraparenchymal hemorrhage. No cavernous malformation was apparent on MR imaging. Diagnostic angiography revealed arteriovenous shunting from the right anterior and middle cerebral arteries to a large DVA with an associated arteriovenous fistula, with a 3-mm aneurysm in the transition from pericallosal artery to the collecting vein. Both surgical and endovascular treatment options were considered. The patient underwent repeat angiography on hospital Day 7, at which time the aneurysm had increased to $5 \mathrm{~mm}$, and endovascular treatment was selected. Acrylic occlusion of the aneurysm was performed and confirmed angiographically. The patient's neurological symptoms resolved throughout the hospital stay, and he remains symptom free in the 10 months since treatment. Developmental venous anomalies are not usually associated with arteriovenous shunting and aneurysms as a source of intraparenchymal hemorrhage. Endovascular occlusion of the aneurysm without blockage of physiologically necessary venous structures is a possible method of treatment for this complex mixed vascular lesion, and has proven safe and effective in this patient. To the authors' knowledge, this is the first presentation of this situation in the literature. (DOI: 10.3171/2009.1.FOCUSO8291)
\end{abstract}

KEY WORDS $\quad$ arteriovenous fistula $\bullet \quad$ transitional aneurysm $\bullet$
venous malformation $\quad \bullet \quad$ embolization

$\mathrm{I}$ N 1966, McCormick ${ }^{9}$ classified cerebrovascular malformations into 4 categories: AVM, venous angioma, $\mathrm{CM}$, and capillary telangiectasia. Although mixed vascular malformations have been described, ${ }^{1,10,12,16,19}$ McCormick's classification is still widely accepted. Venous angiomas, now referred to as DVAs or cerebral venous malformations, are the most common cerebrovascular lesion in both autopsy ${ }^{17}$ and imaging studies. ${ }^{13,14,21}$ Despite a high incidence, these lesions are rarely a cause of intracerebral hemorrhage. ${ }^{3}$ Because of this vanishingly small risk of hemorrhage, most reports support a conservative approach to DVAs, ${ }^{10}$ and few authors suggest any form of treatment. ${ }^{7,8}$

In this case, we describe the unusual presentation of intracerebral hemorrhage associated with a mixed vascu-

Abbreviations used in this paper: $\mathrm{AVF}=$ arteriovenous fistula $\mathrm{AVM}=$ arteriovenous malformation; $\mathrm{CM}=$ cavernous malformation; DVA = developmental venous anomaly; PerA = pericallosal artery. lar lesion: a DVA with associated arteriovenous shunting more typical of a pial AVM and an aneurysm transitioning from PerA to draining vein. Mixed vascular lesions form a subset of DVAs that may show increased risk of hemorrhage and may therefore necessitate treatment. ${ }^{10}$ This is the first report documenting the successful use of endovascular embolic occlusion of the transitional aneurysm in a lesion of this variety, and it supports the argument for aggressive management of the subset of DVAs that present with hemorrhage. We provide a description of the case along with a discussion of the origins, frequency, and concerns associated with this lesion and its management.

\section{Case Report}

History and Examination. This 33-year-old man without significant medical history developed acute onset of gait ataxia, vertigo, occipital headache, and mild left leg weakness. Brain CT scans obtained without ad- 

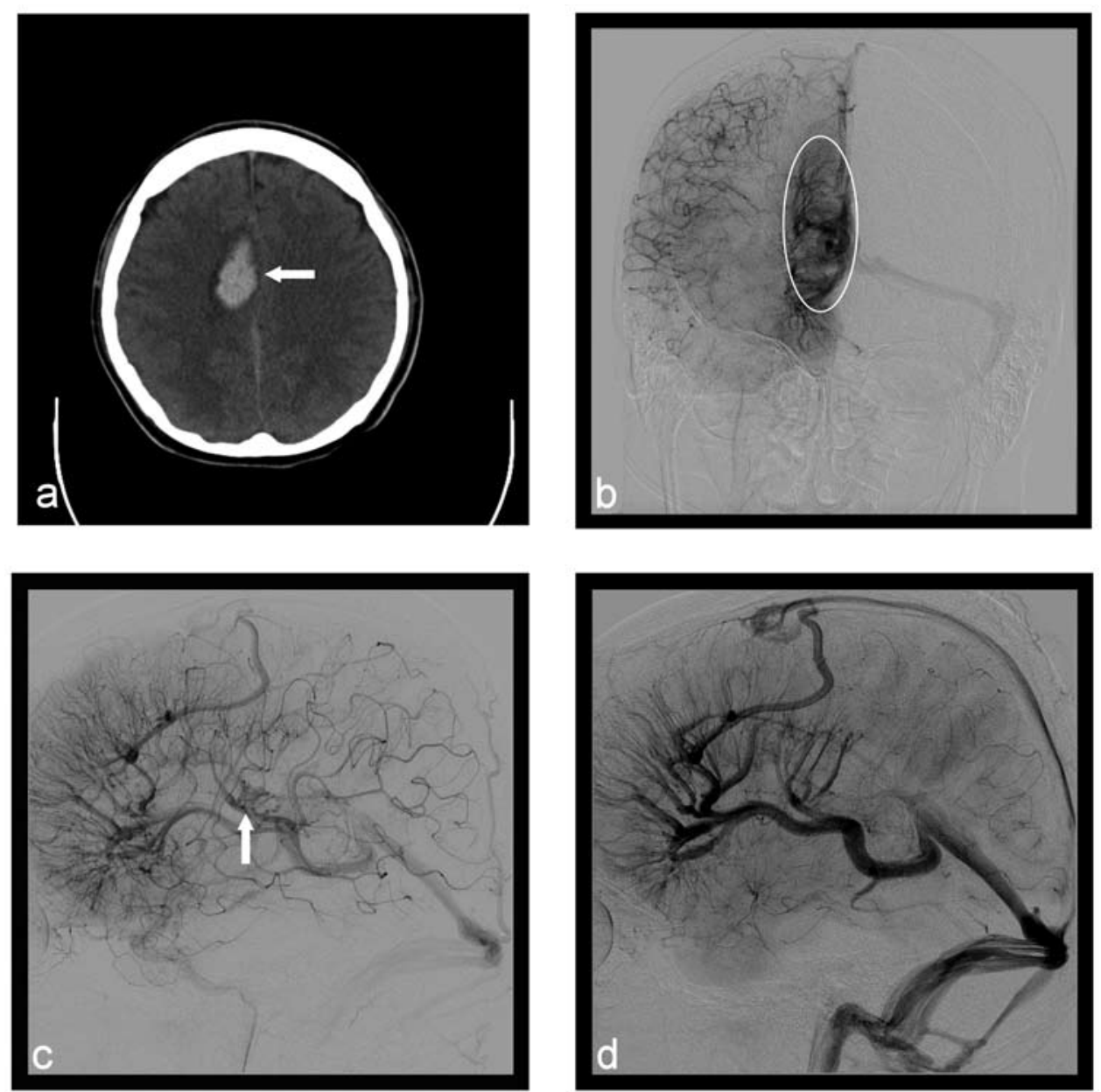

FIG. 1. Axial CT brain scan (a) obtained without addition of contrast material reveals acute parenchymal hemorrhage (arrow) in the medial right frontal lobe above the corpus callosum. Late arterial phase right internal carotid arteriography, anteroposterior (b) and lateral (c) projections, demonstrates arteriovenous shunting (arrow) to a large developmental venous anomaly (circled area) with deep venous drainage predominantly to the right internal cerebral vein. Another lateral projection (d) more clearly demonstrates focal venous outflow stenosis of the vein of Galen proximal to its confluence with the straight sinus as well as collateral drainage to the superior sagittal sinus.

dition of contrast material revealed an acute right frontal intraparenchymal hemorrhage above the corpus callosum (Fig. 1a). Catheter angiography demonstrated a right frontal DVA with associated arteriovenous shunting, and a 3-mm aneurysm arising from the transition between the right PerA and draining vein (Fig. 1b-d). The vascular malformation drained predominantly to the right internal cerebral vein. Over several days, the aneurysm increased in size from $3 \mathrm{~mm}$ at initial diagnosis to $5 \mathrm{~mm}$ at the time of its endovascular occlusion (Fig. 2a and b).

Operation and Postoperative Course. Microcatheter arteriography was performed in the right PerA and a perforator branch arising from this artery, from which the aneurysm formed (Fig. 2c and d). Embolization and occlusion of the transitional aneurysm was then performed using Cordis N-butyl cyanoacrylate (Tru-Fill, JNJ Cordis) mixed with glacial acetic acid and iodized oil (Lipiodol). A control angiography study showed complete occlusion of the aneurysm, without other arterial or venous branch vessel occlusion (Fig. 3). The patient was discharged on hospital Day 12 without residual neurological deficits, and he continues to be in good health through 10 months of ongoing follow-up.

\section{Discussion}

Due to the high incidence but rare clinical presentation of DVAs, they are thought to be relatively benign lesions. ${ }^{3} \mathrm{~A}$ small subset of these lesions, however, is associated with other cerebrovascular abnormalities, such as AVMs, CMs, venous anomalies, and AVFs. ${ }^{10}$ It has been suggested that these mixed cerebrovascular lesions carry an increased risk of hemorrhage, and therefore merit increased monitoring and potentially even treatment. It is unknown whether increased morbidity results from an inherent developmental abnormality in these vessels or if abnormal blood flow and high pressures result in aneurysm formation.

Because of the histological similarities between DVAs and the dilated, single-layered veins of the fetal cerebral vasculature, it has been suggested that DVAs are vestigial remnants of the fetal circulation. ${ }^{19}$ Mullan et al. ${ }^{11}$ 

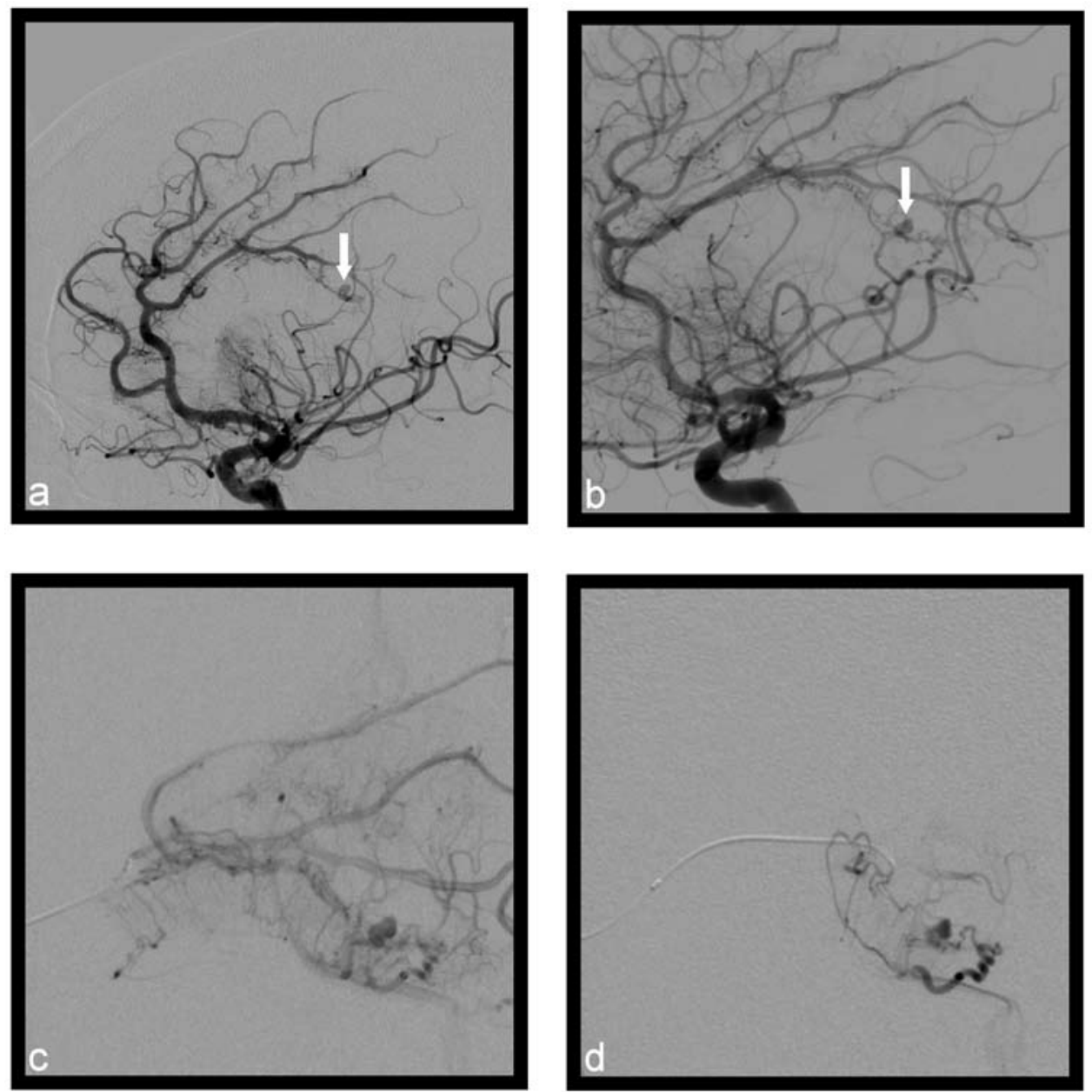

FIG. 2. a: Digital subtraction angiogram revealing a 3-mm transitional aneurysm (arrow) arising from the distal pericallosal branch of the right anterior cerebral artery between the corpus callosum and cingulate gyrus at the location of the hemorrhage. b: Repeat lateral right internal carotid projection performed 1 week postadmission revealing an interval increase in maximal size of the transitional aneurysm to $5 \mathrm{~mm}$ (arrow); the lesion was subsequently embolized. $\mathrm{c}$ and d: Microcatheter injections revealing greater anatomical detail of the aneurysm and venous drainage.

proposed a coherent theory linking the development of DVAs and pial AVMs, suggesting that both form when the fetus is $40-80 \mathrm{~mm}$ in length, during the period of time when pial-to-dural venous connections regress. If excessive numbers of veins draining the cortical venous plexus to the dural venous plexus occlude or if the occlusion spreads into the cortical venous plexus itself, conditions favoring formation of a DVA are created. A deep network of veins that drain to the cortical venous plexus through a single adjoining vein is then likely to develop. The arrangement of an abnormal deep venous network (referred to as a "star"), an adjoining draining vein, and fewer pial veins contains all the elements of a DVA.

Some authors have theorized that this initial malformation then sets the stage for other cerebrovascular abnormalities. If the "star" cluster of deep veins forms a thrombosis, the cluster may form an AVF as the clot is absorbed, as well as recruit an artery to its nidus., ${ }^{4,5,18}$ Furthermore, chronic venous hypertension of 2-3 months duration without associated venous or sinus thrombosis has been shown experimentally to induce dural or subcu- taneous AVF. ${ }^{6,20}$ We suspect that the AVF in this case developed in response to the venous hypertension observed secondary to stenosis of the venous outflow of the DVA (Fig. 1d) and suggested by collateral venous drainage to the superior sagittal sinus, representing a clinical manifestation of the basic mechanisms proposed by the aforementioned experimental studies.

Hemorrhage in the presence of a DVA may result from one of a number of reasons. Case reports have described hemorrhage following thrombotic occlusion of the associated draining veins. ${ }^{2}$ Other authors have found evidence of CMs in the presence of DVAs, and have suggested that occult CMs may play a large role in DVA hemorrhage..$^{15}$ Other studies, however, have examined ruptured DVAs histologically, and found no evidence of associated CMs. ${ }^{23}$ Rarely, venous aneurysms have been reported as a potential source of bleeding. ${ }^{22}$

\section{Conclusions}

With significant associated venous hypertension, 


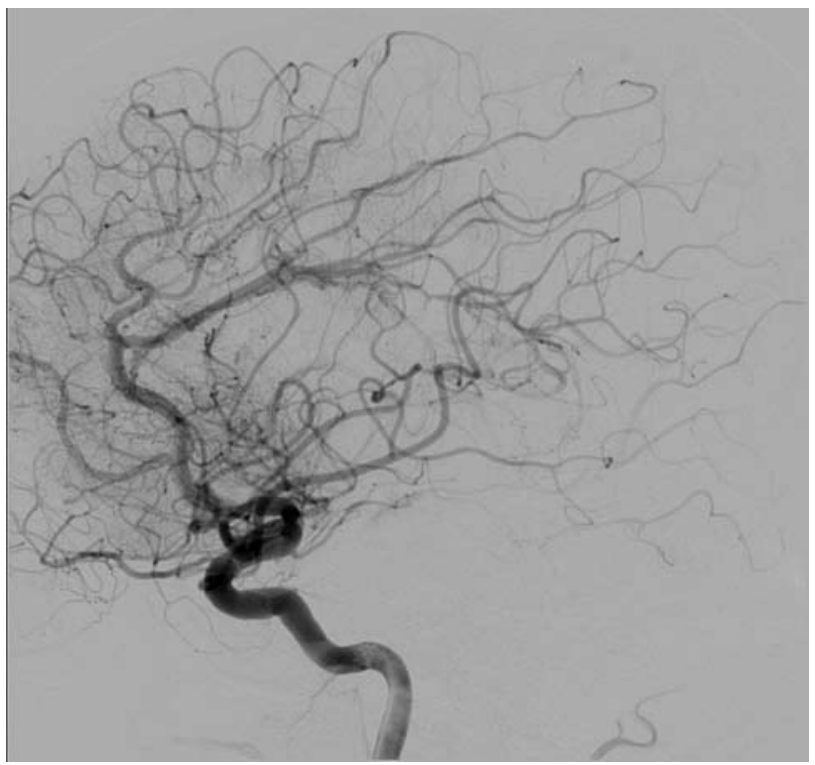

FIG. 3. Postembolization angiogram revealing complete occlusion of the aneurysm.

arteriovenous shunting, and a transitional aneurysm, the DVA in this case exhibited multiple factors increasing the risk of hemorrhage. After observing a dramatic increase in the size of the aneurysm from 3 to $5 \mathrm{~mm}$ over a 1-week period, we suspected that this probably represented a dynamic lesion secondary to abnormally high flow or pressure through the DVA. Due to the symptomatic presentation and the dynamic nature of the lesion, we believed that treatment was merited, and endovascular embolization of the aneurysm was successfully performed. Once the perforating vessel harboring the aneurysm was successfully catheterized, glue was used to embolize the vessel, thus occluding the aneurysm. This avoided the ischemic complications involved with either embolization of the large PerA or compromise of the venous outflow of the DVA. This technique was also used because we believed that catheterizing the aneurysm itself would lead to rupture of its parent artery. In summary, this case provides a rare example of a dynamic venous lesion and the first documented case of its effective treatment with endovascular obliteration of an associated ruptured transitional aneurysm.

\section{Disclaimer}

The authors do not report any conflict of interest concerning the materials or methods used in this study or the findings specified in this paper.

\section{References}

1. Awad IA, Robinson JR Jr, Mohanty S, Estes ML: Mixed vascular malformations of the brain: clinical and pathogenetic considerations. Neurosurgery 33:179-188, 1993

2. Field LR, Russell EJ: Spontaneous hemorrhage from a cerebral venous malformation related to thrombosis of the central draining vein: demonstration with angiography and serial MR. AJNR Am J Neuroradiol 16:1885-1888, 1995

3. Garner TB, Del Curling O Jr, Kelly DL Jr, Laster DW: The natural history of intracranial venous angiomas. J Neurosurg 75:715-722, 1991

4. Herman JM, Spetzler RF, Bederson JB, Kurbat JM, Zabram- ski JM: Genesis of a dural arteriovenous malformation in a rat model. J Neurosurg 83:539-545, 1995

5. Izumi T, Miyachi S, Hattori K, Iizuka H, Nakane Y, Yoshida J: Thrombophilic abnormalities among patients with cranial dural arteriovenous fistulas. Neurosurgery 61:262-269, 2007

6. Lawton MT, Jacobowitz R, Spetzler RF: Redefined role of angiogenesis in the pathogenesis of dural arteriovenous malformations. J Neurosurg 87:267-274, 1997

7. Lindquist C, Guo WY, Karlsson B, Steiner L: Radiosurgery for venous angiomas. J Neurosurg 78:531-536, 1993

8. Malik GM: Venous angiomas: an underestimated cause of intracranial hemorrhage. Surg Neurol 31:482, 1989

9. McCormick WF: The pathology of vascular ("arteriovenous") malformations. J Neurosurg 24:807-816, 1966

10. Meyer B, Stangl AP, Schramm J: Association of venous and true arteriovenous malformation: a rare entity among mixed vascular malformations of the brain. Case report. J Neurosurg 83:141-144, 1995

11. Mullan S, Mojtahedi S, Johnson DL, Macdonald RL: Embryological basis of some aspects of cerebral vascular fistulas and malformations. J Neurosurg 85:1-8, 1996

12. Pritz MB: Ruptured supratentorial arteriovenous malformations associated with venous aneurysms. Acta Neurochir (Wien) 128:150-162, 1994

13. Rigamonti D, Drayer BP, Johnson PC, Hadley MN, Zabramski J, Spetzler RF: The MRI appearance of cavernous malformations (angiomas). J Neurosurg 67:518-524, 1987

14. Rigamonti D, Spetzler RF: The association of venous and cavernous malformations. Report of four cases and discussion of the pathophysiological, diagnostic, and therapeutic implications. Acta Neurochir (Wien) 92:100-105, 1988

15. Rigamonti D, Spetzler RF, Drayer BP, Bojanowski WM, Hodak J, Rigamonti KH, et al: Appearance of venous malformations on magnetic resonance imaging. J Neurosurg 69:535-539, 1988

16. Sadatomo T, Yuki K, Murakami T, Migita K, Taniguchi E, Kodama Y: A case of venous angioma with arteriovenous shunts-case report. Hiroshima J Med Sci 52:91-97, 2003

17. Sarwar M, McCormick WF: Intracerebral venous angioma. Case report and review. Arch Neurol 35:323-325, 1978

18. Singh V, Meyers PM, Halbach VH, Gress DR, Higashida RT, Dowd CF, et al: Dural arteriovenous fistula associated with prothrombin gene mutation. J Neuroimaging 11:319-321, 2001

19. Tashiro Y, Takeno Y, Mizoguchi T, Maehara F: Medullary venous malformation with an arterial component associated with a ruptured aneurysm-case report. Neurol Med Chir (Tokyo) 29:857-860, 1989

20. Terada T, Higashida RT, Halbach VV, Dowd CF, Tsuura M, Komai N, et al: Development of acquired arteriovenous fistulas in rats due to venous hypertension. J Neurosurg 80:884889,1994

21. Toro VE, Geyer CA, Sherman JL, Parisi JE, Brantley MJ: Cerebral venous angiomas: MR findings. J Comput Assist Tomogr 12:935-940, 1988

22. Tyson GW, Jane JA, Strachan WE: Intracerebral hemorrhage due to ruptured venous aneurysm. Report of two cases. J Neurosurg 49:739-743, 1978

23. Wilms G, Demaerel P, Marchal G, Baert AL, Plets C: Gadolinium-enhanced MR imaging of cerebral venous angiomas with emphasis on their drainage. J Comput Assist Tomogr 15:199-206, 1991

Manuscript submitted December 1, 2008.

Accepted January 20, 2009.

Address correspondence to: Andrew F. Ducruet,M.D.,Department of Neurological Surgery, Columbia University, 630 West 168th Street, Room 5-454, New York, New York 10032. email: afd12@ columbia.edu. 